\title{
Research Paper: Comparison of Health-Related Quality of Life in Patients With Various Types of Multiple Sclerosis
}

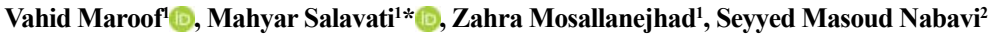 \\ 1. Department of Physiotherapy, University of Social Welfare and Rehabilitation Sciences, Tehran, Iran. \\ 2. Department of Internal Medicine, Faculty of Medicine, Shahed University of Medical Sciences, Tehran, Iran.
}

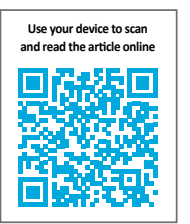

Chtation Maroof V, Salavati M, Mosallanejhad Z, Nabavi SM. Comparison of Health-Related Quality of Life in Patients With Various Types of Multiple Sclerosis. Physical Treatments. 2017; 7(3):175-184. http://dx.doi.org/10.32598/ptj.7.3.175

: http://dx.doi.org/10.32598/ptj.7.3.175

Funding: See Page 183

(c) Copyright: The Author(s)

Article info:

Received: 20 Feb 2017

Accepted: 10 Jun 2017

Available Online: 01 Oct 2017

Keywords:

Multiple Sclerosis, Healthrelated quality of life, SF-36, COOP/WONCA

\begin{abstract}
A B S T RA C T
Purpose: Chronic diseases affect patients' Quality of Life (QoL) and even their caregivers. By evaluating the QoL of patients with multiple sclerosis, the undiagnosed problems of the patients can be detected and the appropriate treatment objectives can be determined. This study was conducted to evaluate the QoL in patients with different types of MS.
\end{abstract}

Methods: A total of 314 patients with Multiple Sclerosis (MS) referred to "Society for the support of MS patients", "Raad Charity and Education complex", and an outpatient clinic in Tehran during fall and winter 2014-2015 were recruited. All patients completed the 36-Item Short Form questionnaire (SF-36) and Dartmouth Coop Functional Health Assessment/World Organization of National Colleges, Academies and Academic Association of General Practitioners (COOP/ WONCA) functional health assessment charts as self-report.

Results: To investigate the research hypothesis and analyzing the results of the two questionnaires, 1-way analysis of variance (ANOVA) was used. The results of the analysis showed a significant difference between the three types of MS (relapsing-remitting, secondary progressive and primary progressive) in the scores of all SF-36 questionnaire subscales. A significant difference was also found between the three types of MS regarding the scores of all charts of COOP/WONCA, except for social support. Then with the use of LSD post hoc test, scores of both questionnaires subscales in these three types of MS were pair-wisely compared.

Conclusion: The results showed that the type of MS disease can affect the patients' QoL. Patients with relapsing-remitting MS had the best level of QoL among all others. The COOP/WONCA charts were more sensitive in measuring the differences between the secondary-progressive MS and primary-progressive MS.

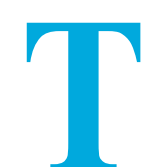

\section{Introduction}

he main purpose of evidence-based medicine in treating debilitating diseases like Multiple Sclerosis (MS) is to reduce the impact of disease on patient's lives and ensures of the positive effects of therapeutic interventions on their Quality of Life (QoL) [1]. Today, it is well-known that address-

\section{* Corresponding Author:}

Mahyar Salavati, $P h D$

Address: Department of Physiotherapy, University of Social Welfare and Rehabilitation Sciences, Tehran, Iran

Phone: +98 (915) 1736765

E-mail: mahyarsalavati@gmail.com 
ing psychical disabilities alone, despite its importance, does not reflect all important aspects of patient's lives. Quality of life goes beyond physical health which constitutes only one feature of MS complications. As a result, evaluating the QoL based on patient's view is one of the most important methods to explore the effects of different treatments on disease course $[2,3]$.

Over the past decades, the concept of health-related quality of life has become increasingly important, and its quantitative and qualitative assessments have been decisive methods in measuring society health status and therapeutic approaches $[4,5]$. During the past decade, the topic of QoL in MS has been studied more than other neurological disorders [6]. The researchers have reported that MS has a higher negative effect on patient's QoL compared to other chronic diseases like rheumatoid arthritis and inflammatory bowel syndrome $[7,8]$. Since chronic illnesses affect the QoL of patients and even their caregivers, studying the QoL of individuals could be an appropriate way to evaluate health care services, provided to them. Regarding the condition of these patients, the importance of assessing their QoL is increasing in the field of rehabilitation sciences. Moreover, the main objective of rehabilitation is to improve the QoL [9].

In 1996, The National Multiple Sclerosis Society of the United States classified 4 clinical stages for the disease; relapsing-remitting, primary-progressive, secondary-progressive, and progressive-relapsing [10]. Exploring QoL of patients with MS not only assists identifying patient's undiagnosed problems, but also leads to better determination of therapeutic goals. Therefore, the present study aimed at evaluating QoL of patients with MS, with the use of two generic tools. We could define the most appropriate therapeutic goals by identifying necessities, problems, and differences of each of the above-mentioned groups of MS patients. Although both assessment instruments measure health-related QoL, one specifically emphasizes on assessing physical performance $[5,11]$.

\section{Materials and Methods}

A total number of 314 patients diagnosed with MS referred to "Society for the support of MS patients", "Raad Charity and Education complex" and a Neurology Specialist's (An MS fellowship) office in Tehran during fall and winter 2014-2015, participated in this study. Samples were collected by the non-probability sampling method. The inclusion criteria consisted of residence in Iran, speaking Persian as their native language, being diagnosed with MS disease for at least 6 months, 18 years of age or older, and being educated up to high-school.

The exclusion criteria were inability to fill out the questionnaire independently due to reasons such as vision problems, severe weakness of the upper limbs, experiencing an extreme recurrence episode of the disease, presence of other medical conditions like rheumatic diseases, heart diseases, neurological disorders, malignant tumors, orthopedic diseases and diabetes (diagnosed by a specialist that noted in patients' medical records or reported directly by the patient). After choosing the participants based on inclusion and exclusion criteria, in the next step, we explained the research procedure and main study objectives to all participants and they have voluntarily signed the informed consent. The neurologist collected the information regarding the type of MS disease by the Expanded Disability Status Scale (EDSS) and demographic data questionnaire was used to gather individual information of the patients. In addition, two self-reported questionnaires were used to collect data; the Persian version of 36-Item Short Form Questionnaire (SF-36) and, the Persian version of Dartmouth Coop Functional Health Assessment/ World Organization of National Colleges, Academies and Academic Association of General Practitioners (COOP WONCA).

In 2005, the Persian version of SF-36 questionnaire was applied on the Iranian population and has been proven reliable and valid for measuring QoL in Iran [12]. This inventory consists of 8 subscales, including physical functioning, role-physical problems, role-emotional problems, vitality, mental health, social functioning, bodily pain, and general health. Each subscale is scored based on adding all scores of questions related to that subscale, then the sum is averaged and recorded as the score of that subscale. It ranges from 0 (the worst case) to 100 (the best case) [13].

The COOP/WONCA questionnaire was also translated into Persian in 2013 and its psychometric properties were examined on the Iranian population [14]. COOP/ WONCA is a self-report tool consisting of 9 subscales, each containing an item and evaluating one aspect of functional abilities, including physical fitness, feelings, daily activities, social activity, pain, change in health, overall health, social support and, quality of life. Each item has a 5-point scale, i.e. 1: best status, 5: worst status. This inventory mainly emphasizes on the assessment of physical functions [15]. 


\section{Results}

The current study was conducted on 314 patients with MS disease during fall and winter 2014-2015. The participants included 68(21.7\%) males and 246(78.3\%) females, with the Mean (SD) age of 34.6(8.4) years. Most of the patients $(81.2 \%)$ were classified in RRMS (Relapsing-Remitting) group and no patient with PRMS (Progressive-Relapsing) was involved in this study. Tables 1 and 2 present the participant's demographic data. The scores of SF-36 and COOP/WONCA are presented in Table 3.

The highest mean score of the SF-36 questionnaire was obtained from the subscale of 'bodily pain' and the lowest mean score belonged to 'role-emotional problems'. Furthermore, 'physical fitness' and 'social activity' were noted as the highest and lowest mean scores, obtained from COOP/WONCA questionnaire, respectively. According to the results of 1-way ANOVA, all subscale scores of SF-36 questionnaire were significantly different among groups of patients with different types of MS disease (RRMS, SPMS, PPMS) (Table 4).

Results of the LSD post hoc test revealed a statistically significant difference between PRMS and SPMS patients in all subscales of SF-36 questionnaire, expect for 'mental health'. To improve decision making about the difference between the studied groups, the effect size was also measured by Cohen's d. Cohen proposed a certain type of classification to determine the effect size, so that 0.2 or below has been defined as small, 0.5 as medium, and 0.8 or above as large effect size [16].

Such difference was higher in the 'physical functioning', compared to other subscales (according to the effect size). There was a difference between PRMS and PPMS patients in all subscales of the SF-36 questionnaire. According to the results, this difference was greater in the 'physical functioning' (according to the effect size) than other subscales. There was no significant difference between SPMS and PPMS patients in any subscale of SF-36 questionnaire (Table 5). Our data obtained from 1-way ANOVA test demonstrated that scores of all subscales of COOP/WONCA questionnaire, expect for the 'social support', were significantly different in patients with three different types of MS disease (RRMS, SPMS, PPMS) (Table 6).

The results of LSD post hoc test showed a significant difference between PRMS and SPMS patients in all scores of COOP/WONCA questionnaire, expect for 'social support and 'feelings' subscales. This difference was more in 'daily activities' (according to the effect size) compared to other subscales. There was also a significant difference between RRMS and PPMS patients in all subscales of questionnaire, except for 'social support'. This difference was more in 'daily activities' subscale (according to the effect size) compared to other subscales. There was a significant difference between

Table 1. Qualitative data of the study patients

\begin{tabular}{|c|c|c|c|}
\hline Variable & Groups & No. & $\%$ \\
\hline & Male & 68 & 21.7 \\
\hline \multicolumn{4}{|l|}{ Gender } \\
\hline & Female & 246 & 78.3 \\
\hline \multirow{3}{*}{ Type of MS disease } & RRMS & 255 & 81.2 \\
\hline & SPMS & 48 & 15.3 \\
\hline & PPMS & 11 & 3.5 \\
\hline
\end{tabular}

PHYSICAL TREA $\ M E N T S$

Abbreviations: RRMS: Relapsing-Remitting MS; SPMS: Secondary-Progressive MS; PPMS: Primary-Progressive MS

Table 2. Quantitative data of the study patients

\begin{tabular}{|c|c|c|c|c|c|c|c|}
\hline Variable & No. & Percentage of Missed Data & Min & Max & Domain & Mean & SD \\
\hline Age, $y$ & 314 & 0 & 18 & 66 & 48 & 34.6 & 8.41 \\
\hline Illness duration, y & 314 & 0 & 0.5 & 33 & 32.5 & 6.6 & 5.5 \\
\hline EDSS & 314 & 0 & 0 & 7 & 7 & 1.65 & 2.03 \\
\hline
\end{tabular}


Table 3. Subscale scores of SF-36 and COOP/WONCA questionnaires

\begin{tabular}{|c|c|c|c|c|c|c|c|c|}
\hline & Variable & Number & Percent of Missed Data & Lowest Data & Highest Data & Domain & Mean & SD \\
\hline \multirow{8}{*}{ 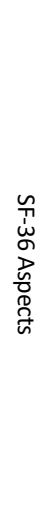 } & Physical functioning & 314 & 0 & 0 & 100 & 100 & 64.37 & 31.16 \\
\hline & Role-physical problems & 314 & 0 & 0 & 100 & 100 & 57.84 & 39.07 \\
\hline & Role-emotional problems & 314 & 0 & 0 & 100 & 100 & 56.35 & 41.54 \\
\hline & Vitality & 314 & 0 & 0 & 100 & 100 & 56.42 & 22.44 \\
\hline & Mental health & 314 & 0 & 0 & 100 & 100 & 61.35 & 20.98 \\
\hline & Social functioning & 314 & 0 & 0 & 100 & 100 & 64.57 & 27.83 \\
\hline & Bodily pain & 314 & 0 & 0 & 100 & 100 & 67.01 & 27.78 \\
\hline & General health & 314 & 0 & 0 & 100 & 100 & 59.64 & 22.43 \\
\hline \multirow{9}{*}{ 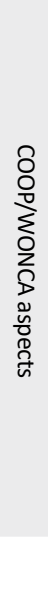 } & Physical fitness & 298 & 5.1 & 1 & 5 & 4 & 3.06 & 1.41 \\
\hline & Feelings & 313 & 0.3 & 1 & 5 & 4 & 2.86 & 1.18 \\
\hline & Daly activities & 314 & 0 & 1 & 5 & 4 & 2.22 & 1.17 \\
\hline & Social activity & 314 & 0 & 1 & 5 & 4 & 2.04 & 1.14 \\
\hline & Pain & 314 & 0 & 1 & 5 & 4 & 2.64 & 1.30 \\
\hline & Change in health & 313 & 0.3 & 1 & 5 & 4 & 2.54 & 0.91 \\
\hline & Overall health & 313 & 0.3 & 1 & 5 & 4 & 2.97 & 1.14 \\
\hline & Social support & 310 & 1.3 & 1 & 5 & 4 & 2.62 & 1.24 \\
\hline & Quality of Life & 313 & 0.3 & 1 & 5 & 4 & 2.50 & 1.00 \\
\hline
\end{tabular}

SPMS and PPMS patients in the subscales of 'feelings', 'social activities', 'pain' and 'general health' of the COOP/WONCA questionnaire. This difference was higher in 'general health' (according to the effect size) in comparison with other subscales (Table 7).

Table 4. Comparing mean score of SF-36 questionnaire subscales with respect to different types of MS disease

\begin{tabular}{|c|c|c|c|c|}
\hline Variable & Type of MS & Mean & SD & $\mathbf{P}$ \\
\hline \multirow{3}{*}{ Physical functioning } & RRMS & 73.30 & 26.12 & \multirow{3}{*}{$<0.001$} \\
\hline & SPMS & 26.44 & 18.74 & \\
\hline & PPMS & 22.72 & 23.59 & \\
\hline \multirow{3}{*}{ Role-physical problems } & RRMS & 66.31 & 36.34 & \multirow{3}{*}{$<0.001$} \\
\hline & SPMS & 22.39 & 29.28 & \\
\hline & PPMS & 15.90 & 20.22 & \\
\hline \multirow{3}{*}{ Role-emotional problems } & RRMS & 61.93 & 40.98 & \multirow{3}{*}{$<0.001$} \\
\hline & SPMS & 36.11 & 36.27 & \\
\hline & PPMS & 15.15 & 22.91 & \\
\hline
\end{tabular}




\begin{tabular}{|c|c|c|c|c|}
\hline Variable & Type of MS & Mean & SD & $\mathbf{P}$ \\
\hline & RRMS & 59.09 & 21.82 & \\
\hline \multirow[t]{3}{*}{ Vitality } & SPMS & 47.11 & 20.85 & $<0.001$ \\
\hline & PPMS & 35.00 & 22.69 & \\
\hline & RRMS & 62.84 & 20.78 & \\
\hline \multirow[t]{3}{*}{ Mental health } & SPMS & 56.64 & 21.60 & 0.013 \\
\hline & PPMS & 47.27 & 15.36 & \\
\hline & RRMS & 68.18 & 27.63 & \\
\hline \multirow[t]{3}{*}{ Social functioning } & SPMS & 51.04 & 22.74 & $<0.001$ \\
\hline & PPMS & 39.77 & 22.92 & \\
\hline & RRMS & 71.31 & 26.44 & \\
\hline \multirow[t]{3}{*}{ Bodily pain } & SPMS & 51.56 & 26.72 & $<0.001$ \\
\hline & PPMS & 34.54 & 16.27 & \\
\hline & RRMS & 63.57 & 21.25 & \\
\hline \multirow[t]{2}{*}{ General health } & SPMS & 44.14 & 19.24 & $<0.001$ \\
\hline & PPMS & 35.90 & 18.81 & \\
\hline
\end{tabular}

PHYSICAL TREA $\$ MENTS

Abbreviations: RRMS: Relapsing-Remitting MS; SPMS: Secondary-Progressive MS; PPMS: Primary-Progressive MS

\section{Discussion}

Overall, findings of this study based on both questionnaires showed that the general health status and quality of life in patients with Relapsing-Remitting MS (RRMS) was higher than the two other groups of Pri-
mary-Progressive MS (PPMS) and Secondary-Progressive MS (SPMS). Our results agree with the findings of prior similar research in this area [17-20]. In addition, the results show that only COOP/WONCA questionnaire was capable of recognizing differences between the SPMS and PPMS groups.

Table 5. LSD post hoc test to pair-wisely compare SF-36 questionnaire subscales mean scores in different types of MS disease

\begin{tabular}{|c|c|c|c|}
\hline Variable & Type of MS & Difference Between Means & Cohen's d \\
\hline \multirow{3}{*}{ Physical functioning } & RRMS-SPMS & $46.87^{*}$ & 1.50 \\
\hline & RRMS-PPMS & $50.57^{*}$ & 1.62 \\
\hline & SPMS- PPMS & 3.70 & 0.11 \\
\hline \multirow{3}{*}{ Role-physical problems } & RRMS-SPMS & $43.92 *$ & 1.12 \\
\hline & RRMS-PPMS & $50.40^{*}$ & 1.29 \\
\hline & SPMS- PPMS & 6.48 & 0.16 \\
\hline \multirow{3}{*}{ Role-emotional problems } & RRMS-SPMS & $25.81^{*}$ & 0.62 \\
\hline & RRMS-PPMS & $46.77^{*}$ & 1.12 \\
\hline & SPMS- PPMS & 20.95 & 0.50 \\
\hline
\end{tabular}




\begin{tabular}{|c|c|c|c|}
\hline Variable & Type of MS & Difference Between Means & Cohen's d \\
\hline \multirow{3}{*}{ Vitality } & RRMS-SPMS & $11.97^{*}$ & 0.53 \\
\hline & RRMS-PPMS & $24.09 *$ & 1.07 \\
\hline & SPMS- PPMS & 12.11 & 0.54 \\
\hline \multirow{3}{*}{ Mental health } & RRMS-SPMS & 6.19 & 0.29 \\
\hline & RRMS-PPMS & $15.57^{*}$ & 0.74 \\
\hline & SPMS- PPMS & 9.37 & 0.44 \\
\hline \multirow{3}{*}{ Social functioning } & RRMS-SPMS & $17.14^{*}$ & 0.61 \\
\hline & RRMS-PPMS & $28.41 *$ & 1.02 \\
\hline & SPMS- PPMS & 11.26 & 0.40 \\
\hline \multirow{3}{*}{ Bodily pain } & RRMS-SPMS & $19.75^{*}$ & 0.71 \\
\hline & RRMS-PPMS & $36.76^{*}$ & 1.32 \\
\hline & SPMS- PPMS & 17.01 & 0.61 \\
\hline \multirow{3}{*}{ General health } & RRMS-SPMS & $19.43^{*}$ & 0.86 \\
\hline & RRMS-PPMS & $27.66^{*}$ & 1.23 \\
\hline & SPMS- PPMS & 8.23 & 0.36 \\
\hline
\end{tabular}

* $\mathrm{P}<0.05$

PHYSICAL TREA $\mid$ MENTS

Abbreviations: RRMS: Relapsing-Remitting MS; SPMS: Secondary-Progressive MS; PPMS: Primary-Progressive MS

In contrast with our findings, Beiske et al. reported the highest degree of QoL in patients with SPMS. They argued that SPMS patients gradually learn to cope with MS disease challenges during the long period of this MS type compared to the other types of MS [21]. In addition, several other studies on other chronic diseases have also documented that the longer the duration of disease, the higher the patient's life satisfaction would be (despite progress of the disease) due to acceptance of their condition and learning to cope with it [22-25].
Considering findings of the current study and many other previous research studies, higher scores of QoL among patients with RRMS could be attributed to the lower degree of disability in this type compared to the other two types of MS disease. Meanwhile, appropriate medication treatment could prevent relapse episodes of RRMS, whilst only symptomatic treatment is done on the other two types of MS disease [26-28].

Table 6. Comparing mean score of COOP/WONCA subscales in different types of MS disease

\begin{tabular}{lcccc}
\hline Variable & Type of MS & Mean & SD & P \\
\hline & RRMS & 2.79 & 1.336 & $<0.001$ \\
Physical fitness & SPMS & 4.20 & 1.173 & 1.009 \\
PPMS & 4.27 & 1.191 & 0.040 \\
\hline
\end{tabular}




\begin{tabular}{|c|c|c|c|c|}
\hline Variable & Type of MS & Mean & SD & $\mathbf{P}$ \\
\hline & RRMS & 1.93 & 1.011 & \\
\hline \multirow[t]{3}{*}{ Daily activities } & SPMS & 3.44 & 0.943 & $<0.001$ \\
\hline & PPMS & 3.82 & 0.751 & \\
\hline & RRMS & 1.84 & 1.041 & \\
\hline \multirow[t]{3}{*}{ Social activity } & SPMS & 2.85 & 1.185 & $<0.001$ \\
\hline & PPMS & 3.18 & 1.079 & \\
\hline & RRMS & 2.48 & 1.257 & \\
\hline \multirow[t]{3}{*}{ Pain } & SPMS & 3.17 & 1.294 & $<0.001$ \\
\hline & PPMS & 4.18 & 0.603 & \\
\hline & RRMS & 2.43 & 0.908 & \\
\hline \multirow[t]{3}{*}{ Change In health } & SPMS & 2.94 & 0.810 & $<0.001$ \\
\hline & PPMS & 3.27 & 0.647 & \\
\hline & RRMS & 2.78 & 1.120 & \\
\hline \multirow[t]{3}{*}{ Overall health } & SPMS & 3.71 & 0.824 & $<0.001$ \\
\hline & PPMS & 4.18 & 0.751 & \\
\hline & RRMS & 2.60 & 1.294 & \\
\hline \multirow[t]{3}{*}{ Social support } & SPMS & 2.73 & 0.984 & 0.766 \\
\hline & PPMS & 2.73 & 0.905 & \\
\hline & RRMS & 2.37 & 0.989 & \\
\hline \multirow[t]{2}{*}{ Quality of Life } & SPMS & 2.94 & 0.885 & $<0.001$ \\
\hline & PPMS & 3.55 & 0.688 & \\
\hline
\end{tabular}

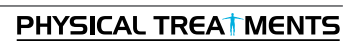

Abbreviations: RRMS: Relapsing-Remitting MS; SPMS: Secondary-Progressive MS; PPMS: Primary-Progressive MS

Other studies that used SF-36 questionnaire showed that lower scores obtained from this tool (lower level of QoL in patients with MS disease) was significantly related with longer duration of illness and its higher severity [29-31]. Leon et al. found that the level of QoL was significantly lower in patients who suffered from MS disease for more than 11 years compared to those who experienced less duration of illness [32]. Although patients find ways to cope with the stress of the disease over time, EDSS (disabilities) of the patient increases in chronic and progressive types of illnesses like MS, and can eventually has a negative impact on their QoL [33].
One of the main limitations of the present study was the lack of involving any patients with PRMS type in the study. Also, only 11 patients with PPMS attended our research, which such a low sample prevents from accurate assessments of this type of MS disease.

Results of the current study show that the type of MS disease can significantly affect patient's QoL, as patients with Relapsing-Remitting MS (RRMS) report highest scores for QoL. According to our findings, physical and motor problems seem to be the most influencing factors in patient's QoL. As a result, setting therapeutic goals to improve the physical condition of 
Table 7. LSD post hoc test to pair-wisely compare COOP/WONCA subscales mean scores in different types of MS disease

\begin{tabular}{|c|c|c|c|}
\hline Variable & Type of MS & Difference Between Means & Cohen's d \\
\hline & RRMS-SPMS & $-1.410^{*}$ & 1 \\
\hline \multirow[t]{3}{*}{ Physical fitness } & RRMS-PPMS & $-1.478^{*}$ & 1.04 \\
\hline & SPMS-PPMS & -0.068 & 0.04 \\
\hline & RRMS-SPMS & -0.099 & 0.08 \\
\hline \multirow[t]{3}{*}{ Feelings } & RRMS-PPMS & $-0.912^{*}$ & 0.77 \\
\hline & SPMS- PPMS & $-0.812^{*}$ & 0.68 \\
\hline & RRMS-SPMS & $-1.512^{*}$ & 1.29 \\
\hline \multirow[t]{3}{*}{ Daily activities } & RRMS-PPMS & $-1.893^{*}$ & 1.61 \\
\hline & SPMS- PPMS & -0.381 & 0.32 \\
\hline & RRMS-SPMS & $-1.019^{*}$ & 0.89 \\
\hline \multirow[t]{3}{*}{ Social activities } & RRMS-PPMS & $-1.347^{*}$ & 1.18 \\
\hline & SPMS- PPMS & $-1.347^{*}$ & 1.18 \\
\hline & RRMS-SPMS & $-0.688^{*}$ & 0.52 \\
\hline \multirow[t]{3}{*}{ Pain } & RRMS-PPMS & $-1.703^{*}$ & 1.31 \\
\hline & SPMS- PPMS & $-1.015^{*}$ & 0.78 \\
\hline & RRMS-SPMS & $-0.504^{*}$ & 0.55 \\
\hline \multirow[t]{3}{*}{ Change in health } & RRMS-PPMS & $-0.840 *$ & 0.92 \\
\hline & SPMS- PPMS & -0.335 & 0.36 \\
\hline & RRMS-SPMS & $-0.925 *$ & 0.81 \\
\hline \multirow[t]{3}{*}{ Overall health } & RRMS-PPMS & $-1.398^{*}$ & 1.22 \\
\hline & SPMS- PPMS & $-1.398^{*}$ & 1.22 \\
\hline & RRMS-SPMS & -0.132 & 0.10 \\
\hline \multirow[t]{3}{*}{ Social support } & RRMS-PPMS & -0.130 & 0.10 \\
\hline & SPMS- PPMS & 0.002 & 0.001 \\
\hline & RRMS-SPMS & $-0.563^{*}$ & 0.56 \\
\hline \multirow[t]{2}{*}{ Quality of Life } & RRMS-PPMS & $-1.171^{*}$ & 1.17 \\
\hline & SPMS- PPMS & -0.608 & 0.60 \\
\hline
\end{tabular}

* $\mathrm{P}<0.05$.

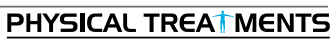

Abbreviations: RRMS: Relapsing-Remitting MS; SPMS: Secondary-Progressive MS; PPMS: Primary-Progressive MS 
patients may enhance their QoL. It is worth mentioning that the sensitivity of the COOP/WONCA questionnaire was higher than other questionnaire in distinguishing differences between SPMS and PPMS.

\section{Ethical Considerations}

\section{Compliance with ethical guidelines}

The study design and methodology were approved by the Ethics Committee of the University of Social Welfare and Rehabilitation Sciences.

\section{Funding}

This research was extracted from the MSc. thesis of the first author, in the Department of Physiotherapy, University of Social Welfare and Rehabilitation Sciences.

\section{Conflict of interest}

The authors declared no conflict of interest.

\section{Acknowledgements}

We would like to sincerely thank "Society for the support of MS patients", "Raad Charity and Education complex" and all patients who kindly participated in this research.

\section{References}

[1] Miller DM, Kinkel RP. Health-related quality of life assessment in multiple sclerosis. Reviews in Neurological Diseases. 2008; 5(2):56-64. [PMID]

[2] Mitchell AJ, Benito-León J, González JMM, Rivera-Navarro J. Quality of life and its assessment in multiple sclerosis: Integrating physical and psychological components of wellbeing. The Lancet Neurology. 2005; 4(9):556-66. [DOI:10.1016/S1474-4422(05)70166-6]

[3] Miller DM, Allen R. Quality of life in multiple sclerosis: Determinants, measurement, and use in clinical practice. Current Neurology and Neuroscience Reports. 2010; 10(5):397-406. [DOI:10.1007/s11910-010-0132-4] [PMID]

[4] Ganz PA. Impact of quality of life outcomes on clinical practice. Oncology. 1995; 9(11):61-5.

[5] Solari A. Role of health-related quality of Life measures in the routine care of people with Multiple Sclerosis. Health Qual Life Outcomes. 2005; 3:16. [DOI:10.1186/1477-75253-16] [PMID] [PMCID]

[6] Benito-León J, Manuel Morales J, Rivera-Navarro J, Mitchell AJ. A review about the impact of multiple sclerosis on health-related quality of life. Disability and Rehabilitation. 2003; 25(23):1291303. [DOI:10.1080/09638280310001608591] [PMID]

[7] Devins GM, Edworthy SM, Seland TP, Klein GM, Paul LC, Mandin H. Differences in illness intrusiveness across rheumatoid arthritis, end-stage renal disease, and Multiple Sclerosis. The Journal of Nervous and Mental Disease. 1993; 181(6):37781. [DOI:10.1097/00005053-199306000-00007] [PMID]

[8] Rudick RA, Miller D, Clough JD. Quality of life in multiple sclerosis: Comparison with inflammatory bowel disease and rheumatoid arthritis. Archives of Neurology. 1992; 49(12):1237-42. [DOI:10.1001/archneur.1992.00530360035014] [PMID]

[9] Benedict RHB, Wahlig E, Bakshi R, Fishman I, Munschauer F, Zivadinov R, et al. Predicting quality of life in multiple sclerosis: accounting for physical disability, fatigue, cognition, mood disorder, personality, and behavior change. Journal of the Neurological Sciences. 2005; 231(1-2):29-34. [DOI:10.1016/j.jns.2004.12.009] [PMID]

[10] Lublin FD, Reingold SC. Defining the clinical course of multiple sclerosis: Results of an international survey. Neurology. 1996; 46(4):907-11. [DOI:10.1212/WNL.46.4.907] [PMID]

[11] Mortensen GL, Rasmussen PV. The impact of quality of life on treatment preferences in multiple sclerosis patients. Patient preference and adherence. 2017;11:1789-96. [DOI:10.2147/ppa.s142373]

[12] Montazeri A, Goshtasebi A, Vahdaninia M, Gandek B. The Short Form Health Survey (SF-36): Translation and validation study of the Iranian version. Quality of Life Research. 2005, 14(3):875-82. [DOI:10.1007/s11136-004-1014-5] [PMID]

[13] Ware JE, Sherbourne CD. The MOS 36-ltem Short-Form Health Survey (SF-36). Medical Care. 1992; 30(6):473-83. [DOI:10.1097/00005650-199206000-00002] [PMID]

[14] Taghipoor M. [Translation, localization and evaluation of the reliability and validity of the Persian version of the COOP WONCA scale in people with multiple sclerosis Persian language Persian language (Persian)] [MSc. thesis]. Tehran: University of Social Welfare and Rehabilitation Sciences; 2013.

[15] Nelson E, Wasson J, Kirk J, Keller A, Clark D, Dietrich A, et al. Assessment of function in routine clinical practice: Description of the coop chart method and preliminary findings. Journal of Chronic Diseases. 1987; 40:55S-63S. [DOI:10.1016/S0021-9681(87)80033-4]

[16] Cohen J. Statistical power analysis for the behavioral sciences. New York: Routledge; 2013. [DOI:10.4324/9780203771587]

[17] Drulovic J, Pekmezovic T, Matejic B, Mesaros S, Manigoda M, Dujmovic I, et al. Quality of life in patients with multiple sclerosis in Serbia. Acta Neurologica Scandinavica. 2007; 115(3):147-52. [DOI:10.1111/j.16000404.2006.00729.x] [PMID]

[18] Gottberg K, Einarsson U, Ytterberg C, de Pedro Cuesta J, Fredrikson S, von Koch L, et al. Health-related quality of life in a population-based sample of people with Multiple Sclerosis in Stockholm County. Multiple Sclerosis Journal. 2006; 12(5):605-12. [DOI:10.1177/1352458505070660] [PMID]

[19] Patti F, Russo P, Pappalardo A, Macchia F, Civalleri L, Paolillo A. Predictors of quality of life among patients with multiple sclerosis: An Italian cross-sectional study. 
Journal of the Neurological Sciences. 2007; 252(2):121-9. [DOI:10.1016/j.jns.2006.10.017] [PMID]

[20] Janardhan V, Bakshi R. Quality of life in patients with multiple sclerosis. Journal of the Neurological Sciences. 2002; 205(1):51-8. [DOI:10.1016/S0022-510X(02)00312-X]

[21] Beiske AG, Baumstarck K, Nilsen RM, Simeoni M-C. Validation of the Multiple Sclerosis International Quality of Life (MusiQoL) questionnaire in Norwegian patients. Acta Neurologica Scandinavica. 2011; 125(3):171-9. [DOI:10.1111/j.1600-0404.2011.01518.x] [PMID]

[22] Albrecht GL, Devlieger PJ. The disability paradox: high quality of life against all odds. Social Science \& Medicine. 1999; 48(8):977-88. [DOI:10.1016/S0277-9536(98)00411-0]

[23] Pittock SJ, Mayr WT, McClelland RL, Jorgensen NW, Weigand SD, Noseworthy JH, et al. Quality of Life Is favorable for most patients with Multiple Sclerosis. Archives of Neurology. 2004; 61(5):679-86. [DOI:10.1001/ archneur.61.5.679] [PMID]

[24] Murray TJ. The psychosocial aspects of Multiple Sclerosis. Neurologic Clinics. 1995; 13(1):197-223. [DOI:10.1016/ S0733-8619(18)30067-7]

[25] Ford HL, Gerry MH, Johnson AH. Health status and quality of life of people with Multiple Sclerosis. Disability and Rehabilitation. 2001; 23(12):516-21. [DOI:10.1080/09638280010022090] [PMID]

[26] Confavreux C, Vukusic S, Moreau T, Adeleine P. Relapses and progression of disability in Multiple Sclerosis. New England Journal of Medicine. 2000; 343(20):1430-8. [DOI:10.1056/NEJM200011163432001] [PMID]

[27] Simeoni M, Auquier P, Fernandez O, Flachenecker P, Stecchi S, Constantinescu C, et al. Validation of the Multiple Sclerosis International Quality of Life questionnaire. Multiple Sclerosis Journal. 2007; 14(2):219-30. [DOI:10.1177/1352458507080733] [PMID]

[28] Fernández O, Fernández V, Baumstarck-Barrau K, Muñoz L, Gonzalez Alvarez M del M, et al. Validation of the Spanish version of the multiple sclerosis international quality of life (musiqol) questionnaire. BMC Neurology. 2011; 11:127. [DOI:10.1186/1471-2377-11-127] [PMID] [PMCID]

[29] Patti F, Cacopardo M, Palermo F, Ciancio MR, Lopes R, Restivo D, et al. Health-related quality of life and depression in an Italian sample of multiple sclerosis patients. Journal of the Neurological Sciences. 2003; 211(1-2):55-62. [DOI:10.1016/S0022-510X(03)00040-6]

[30] Pfennings L, Cohen L, Adèr H, Polman C, Lankhorst G, Smits R, et al. Exploring differences between subgroups of multiple sclerosis patients in health-related quality of life. Journal of Neurology. 1999; 246(7):587-91. [DOI:10.1007/ s004150050408] [PMID]

[31] Merkelbach S, Sittinger H, Koenig J. Is there a differential impact of fatigue and physical disability on quality of life in multiple sclerosis? The Journal of Nervous and Mental Disease. 2002; 190(6):388-93. [DOI:10.1097/00005053200206000-00007] [PMID]

[32] Benito-Leon J, Morales JM, Rivera-Navarro J. Healthrelated quality of life and its relationship to cognitive and emotional functioning in multiple sclerosis patients.
European Journal of Neurology. 2002; 9(5):497-502. [DOI:10.1046/j.1468-1331.2002.00450.x] [PMID]

[33] Ghaem H, Haghighi AB, Jafari P, Nikseresht A. Validity and reliability of the Persian version of the multiple sclerosis quality of life questionnaire. Neurology India. 2007; 55(4):369. [DOI:10.4103/0028-3886.33316] [PMID] 